\title{
Nonalcoholic steatohepatitis (NASH)
}

National Diabetes Information Clearinghouse (NDIC)

\section{Definitions}

Liver

Defined by National Diabetes Information Clearinghouse (NDIC)

Insulin resistance

Defined by National Diabetes Information Clearinghouse (NDIC)

\section{Diabetes}

Defined by National Diabetes Information Clearinghouse (NDIC)

Fat

Defined by National Diabetes Information Clearinghouse (NDIC)

\section{Source}

National Diabetes Information Clearinghouse (U.S.). (2009). The diabetes dictionary. [Bethesda, Md.]: U.S. Dept. of Health and Human Services, National Institutes of Health, National Institute of Diabetes and Digestive and Kidney Diseases,

National Diabetes Information Clearinghouse.

A common liver disease, often without symptoms, that resembles alcoholic liver disease but occurs in people who drink little or no alcohol. The major characteristic of NASH is fat in the liver, along with inflammation and damage. NASH can be a complication of insulin resistance and diabetes. 